\title{
Deposição da calda de pulverização em cultivares de soja no estádio R1
}

\author{
Spray deposition on soybean varietes at $\mathbf{R} 1$ grow stage
}

\author{
Juana Villalba Farinha ${ }^{I^{*}}$ Dagoberto Martins $^{\mathrm{I}}$ Neumarcio Vilanova Costa \\ Vanessa David Domingos ${ }^{\mathrm{I}}$
}

\section{RESUMO}

Com o objetivo de quantificar a quantidade e a uniformidade dos depósitos da calda de pulverização em duas cultivares de soja ('CD 208' e 'CD 216'), no estádio R1, por meio de diferentes pontas e volumes de pulverização, foram conduzidos dois experimentos na área, na Faculdade de Ciências Agronômicas UNESP-Botucatu, São Paulo (SP). Os tratamentos avaliados foram: pontas de jato plano (AI 110015

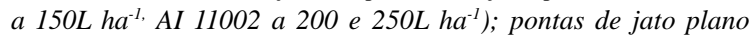
duplo (TJ 6011002 a 150, 200 e 250L ha-1); pontas de jato cônico (TX-6 a 150, TX-8 a 200 e TX-10 a 250L ha-1) e pontas de jato plano duplo e baixa deriva (DGTJ 11002 a $200 \mathrm{~L} \mathrm{ha}^{-1}$ ). O delineamento utilizado foi de blocos ao acaso com quatro repetições. Para a avaliação da deposição, foi utilizado na pulverização o corante Azul Brilhante FDC- 1 (500mg $\left.L^{-1}\right)$. Foram coletadas 25 plantas em cada repetição, divididas em região basal e apical. A determinação do conteúdo depositado foi realizada com a leitura de absorbância no comprimento de onda de 630nm, e os dados transformados em depósitos por grama de matéria seca foram ajustados às curvas de regressão, por meio do modelo de Gompertz. Os maiores depósitos avaliados nas cultivares ' $C D$ 208' e 'CD 216' corresponderam aos tratamentos AI 11002 250L ha-1 e TJ 6011002 250L ha-1, respectivamente. Os resultados da uniformidade da distribuição da calda de pulverização foram contraditórios aos da quantidade de depósitos. Em todas as avaliações, o tratamento de maiores depósitos apresentou menor uniformidade na distribuição.

Palavras-chave: ponta, aplicação, uniformidade de distribuição.

\section{ABSTRACT}

Whit the objective of quantifying the deposits of spraying in two soybean cultivars ('208 CD' and 'CD 216') at R1 grown stage through different nozzles and volumes of

\begin{abstract}
spraying, two experiments were carried out at the experimental area of Agricultural College UNESP-Botucatu/SP. The

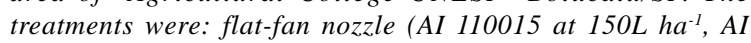
11002 at 200 and 250L ha ${ }^{-1}$ ); twin flat-fan (TJ 6011002 at 150, 200 and 250L ha-1); conical (TX-6 at 150, TX-8 at 200 and TX-10 at 250L ha $\mathrm{ha}^{-1}$ ) and twin flat-fan and low drift (DGTJ 11002 at $200 \mathrm{~L} \mathrm{ha}^{-1}$ ). The experimental design was a randomized completely block, with four replicates. For the evaluation of the deposition Blue courante Shining FDC- 1 was used in the spraying $\left(500 \mathrm{mg} \mathrm{L}^{-1}\right)$. In each replication, 25 plants in had been collected divided in basal and apical section. Deposits content was determinated by absorbance in the wave length of $630 \mathrm{~nm}$, then transformed into deposits per gram of dry matter and adjusted to the regression curves, through the model of Gompertz. The biggest deposits were evaluated with AI 11002

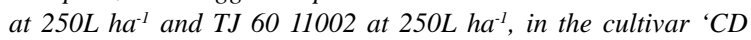
208' and 'CD 216', respectively. Treatments whit the largest deposits showed the minor distribution uniformity.
\end{abstract}

Key words: nozzles, application, uniformity spray.

\section{INTRODUÇÃO}

A soja no Brasil, nos últimos 32 anos sofreu incrementos de $333 \%$ na área cultivada e de 1,536 vezes na produção. Isso consequentemente reverteu em maior uso de produtos fitossanitarios. Essas mudanças estimularam o uso de tecnologias de aplicação de fitossanitários mais acuradas para que os produtos pudessem atingir os alvos.

O sucesso da aplicação e o resultado do controle estão diretamente relacionados aos fatores: seleção de pontas, ajuste do volume da calda, parâmetros operacionais, condições ambientais

'Departamento Produção Vegetal, Faculdade de Ciências Agronômicas, Universidade Estadual Paulista (UNESP), 18610-307,

Botucatu, SP, Brasil. E-mail: villalba@fagro.edu.uy.*Autor para correspondência. 
favoráveis e momento correto da aplicação. Em relação às pontas de pulverização, as diferenças por elas geradas têm a ver com o volume e o tamanho de gotas e ambos, com efeito, na quantidade, penetração e distribuição dos depósitos.

Em estudo de avaliação das pontas jato plano padrão, jato plano com indução de ar e jato plano duplo em aplicações na cultura da soja, constatou-se que a deposição da calda de pulverização era semelhante na parte superior das plantas, independentemente da ponta utilizada. No entanto, na parte inferior à ponta de jato plano padrão apresentou maiores depósitos. Mesmo assim, não houve diferenças no controle de ferrugem asiática pelo efeito do tipo de ponta, sendo que o fungicida foi eficiente em todos os tratamentos testados e diferenciaram-se da testemunha sem aplicação com $41 \%$ mais de produtividade (CUNHA et al., 2006).

O volume a ser utilizado em uma pulverização depende do modo de ação do produto fitossanitário, do tipo e grau de desenvolvimento do alvo e do equipamento. Atualmente, existe uma tendência à redução do volume de calda aplicado, o que resulta em menor transporte de água ao campo, obtendo-se, com isso, diminuição do custo da aplicação e aumento da capacidade operacional do equipamento de aplicação (MAROCHI, 1993; LIMA \& MACHADO NETO, 2001).

Em estudo de aplicação de fungicida, CUNHA et al. (2006), para o controle de ferrugem asiática no estádio R2 da soja, não acharam diferenças dos volumes de aplicação de 115 e 160L ha-1 no controle da doença, embora o volume maior tenha apresentado maior uniformidade. Em um outro estudo em soja, no qual se avaliou o efeito de volumes de aplicação aos 45 días após a emergência (DAE), o maior volume aplicado apresentou maior índice de penetração e menor relação de quantidade depositada com respeito ao volume total aplicado. Já aos 75DAE a penetração foi menor, explicadaS pela dificuldade de penetração no dossel das folhas (BAUER, 2002).

Considerando todos esses aspectos apresentados, estudaram-se os depósitos da calda de pulverização em duas cultivares de soja ('CD 208' e 'CD 216’), no estádio R1, por meio de diferentes pontas e volumes de pulverização.

\section{MATERIAL E MÉTODOS}

O trabalho foi conduzido na área didática do Departamento de Produção Vegetal e no Laboratório de Matología (NUPAM), pertencentes à Faculdade de Ciências Agronômicas UNESP-Campus de Botucatu/ SP. Foram utilizadas as cultivares ‘CD 208’ (crescimento determinado) e 'CD 216' (crescimento indeterminado), tendo em vista que o desenvolvimento delas difere e elas podem determinar deposições da calda diferentes. A semeadura da cultivar 'CD 208' foi no dia 10/10/2005 e a semeadura da cultivar 'CD 216' em 24/10/2005. Ambas as cultivares receberam adubação conforme as análises de solo, e irrigação, conforme as necessidades da cultura. A densidade foi de 299.700 e 240.000 plantas no hectare para as cultivares 'CD 208' e 'CD 216', respectivamente, semeadas em espaçamento de $0,45 \mathrm{~m}$.

Os tratamentos consistiram da avaliação das pontas de pulverização: (i) ponta AI de jato plano, com diâmetro de gotas grosso e muito grosso; (ii) ponta TJ, de jato plano duplo, com diâmetro de gotas muito fino e fino; (iii) ponta TX, de jato cônico com diâmetro de gotas muito fino; e (iv) ponta DGTJ, de jato plano duplo e baixa deriva com diâmetro de gotas médio, sendo todas fabricadas pela Spraying System do Brasil. As primeiras três pontas foram avaliadas nos volumes de aplicação de 150, 200 e 250L ha-1 para as duas cultivares, no entanto, a ponta DGTJ foi avaliada somente no

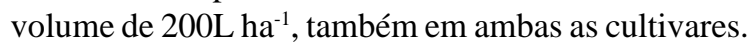
As pressões de trabalho utilizadas foram para a ponta AI, $180 \mathrm{KPa}$, para os primeiros volumes, e 320KPa, para o volume mais alto. No caso da ponta TJ, as pressões foram de 120, 180 e 270KPa para os volumes de 150, 200 e 250 $\mathrm{L} \mathrm{ha}^{-1}$, respectivamente. A ponta TX foi usada em uma pressão de $500 \mathrm{KPa}$ para todos os volumes, alterando, nesse caso, as velocidades de deslocamento para atingir os diferentes volumes. No entanto, para a ponta DGTJ, a pressão utilizada foi de $200 \mathrm{KPa}$.

As aplicações foram realizadas com um pulverizador costal pressurizado a $\mathrm{CO}_{2}$, munido de uma barra com quatro bicos distanciados de $0,5 \mathrm{~m}$ entre si. Estas foram realizadas no dia 3 e no dia 4/12/2005, no caso do cultivar 'CD 208'. Já, na cultivar 'CD 216', a aplicação foi realizada nos dias 12 e 13/12/2005. A velocidade do vento para ocasião de ambos os experimentos encontrava-se em forma de rajadas e variava de 2 a $3 \mathrm{~km} \mathrm{~h}^{-1}$. Não houve condições limitantes de temperatura e umidade relativa.

Para as avaliações de depósitos nas plantas, as pulverizações foram realizadas com um traçador alimentício, o corante Azul Brilhante (FDC-1), diluído em razão de 500 $\mathrm{mg} \mathrm{L}^{-1}$, em água destilada. Após a aplicação, 100 plantas foram retiradas mantendo-as individualizadas, com a divisão em parte apical e basal. Logo foram colocadas em sacolas plásticas para sua lavagem com 200mL de água destilada, para a remoção do corante. A solução da lavagem foi quantificada no espectrofotômetro de feixe duplo de UV- visível, para a leitura de absorbância no comprimento de onda de 630nm. As leituras de absorbância foram ajustadas à 
curva-padrão estabelecida e foram transformadas por meio de uma equação matemática, obtendo-se, assim, o volume de calda depositado em $\mathrm{mL} \mathrm{g}^{-1}$ massa seca, seguindo a descrição de PALLADINI (2000).

Os dados obtidos foram submetidos à análise de regressão ajustada ao modelo de Gompertz, $\mathrm{Y}=\mathrm{e}^{\wedge \wedge}\left(\mathrm{A}-\mathrm{e}^{\wedge \wedge}\left(-\mathrm{B}-\mathrm{C}^{*} \mathrm{X}\right)\right)$, seguindo procedimentos descritos por VELINI (1995), em que para, A: valor máximo da assíntota da curva, adotou-se o valor 4,60517, de modo que $\mathrm{e}^{\mathrm{a}=100 ;} \mathrm{B}$ : deslocamento da curva ao longo do eixo X; C: inclinação ou concavidade da curva em relação às respectivas frequências $\mathrm{Y}$; X: porcentagem de depósitos do traçador.

Foram determinadas a frequência acumulada em função dos depósitos do corante e a frequência não acumulada dos depósitos, por meio do cálculo da derivada primeira da frequência acumulada, o que permitiu avaliar a uniformidade da distribuição da calda de pulverização.

Para a comparação da deposição nas duas cultivares, realizou-se análise conjunta. Para comparar as variâncias, foram estimadas as variâncias do erro de cada cultivar e comparadas pelos intervalos de confiança a 95\%. Quando as variâncias não foram estatisticamente diferentes, usou-se um modelo simplificado com variância única, com o procedimento MIXED do pacote estatístico SAS.

\section{RESULTADOS E DISCUSSÃO}

O estudo de homogeneidade de variâncias, a partir do procedimento MIXED, foi significativo e permitiu a análise conjunta dos dois experimentos, por isso são apresentados os resultados das duas cultivares em forma conjunta.

A análise comparativa da deposição, na região apical das duas cultivares, permitiu constatar que, na cultivar 'CD 208', somente a ponta AI 250L ha'-1 ocasionou depósitos superiores estatisticamente das restantes pontas. Na cultivar 'CD 216', foram as pontas TJ 250L ha-1 e AI 200L ha-1 as que apresentaram depósitos significativamente superiores, não diferindo esta última com os depósitos da ponta TX-10 250L ha-1 (Tabela 1). Destaca-se a deposição das pontas AI 250L ha $^{-1}$ e TJ 150L ha-1 com quantidade de depósitos estatisticamente superiores na cultivar 'CD 208' comparada à cultivar 'CD 216'. Isso poderia ser explicado, no caso da ponta $\mathrm{AI}$, porque essa ponta gera gotas maiores e em menor quantidade e que não atingiram plantas com maior desenvolvimento como o apresentado pela cultivar 'CD 216’. A matéria seca média de cada planta era quase $40 \%$ mais que na cultivar ' $C D$ 208' (g massa seca/planta ‘CD 208': 5,21; g massa seca/ planta CD 216: 7,18).

Tabela 1 - Comparação da deposição da calda de pulverização ( $\mu \mathrm{L} \cdot \mathrm{g}^{-1}$ massa seca) nas cultivares ‘CD 208' e ‘CD 216’, em R1, na região apical. Botucatu/SP, 2005.

\begin{tabular}{|c|c|c|c|}
\hline Ponta de pulverização & Volume aplicação (L.ha $\left.{ }^{-1}\right)$ & ‘CD 208’ & ‘CD 216’' \\
\hline AI 110015 & 150 & 199,09 abc $A$ & 134,16 ef $\mathrm{A}$ \\
\hline AI 11002 & 200 & 212,83 abc $A$ & $280,81 \mathrm{ab} A$ \\
\hline AI 11002 & 250 & 327,01 a A & 174,41 de $B$ \\
\hline T J 11002 & 150 & 210,59 abc A & 108,11 f B \\
\hline TJ 11002 & 200 & 174,09 bc A & 183,45 cde A \\
\hline T J 11002 & 250 & 248,32 ab A & 329,11 a A \\
\hline TX 6 & 150 & 101,61 с A & 92,84 f A \\
\hline TX 8 & 200 & 213,54 abc A & 208,76 cd A \\
\hline TX 10 & 250 & 201,84 abc A & 233,31 bc $A$ \\
\hline DGT J & 200 & 182,85 bc A & 219,11 cd A \\
\hline F cultivar & & 0,44 ns & \\
\hline $\mathrm{F}$ trat & & $4,54 * *$ & \\
\hline F cultivar Xtrat. & & $2,14^{*}$ & \\
\hline
\end{tabular}

Médias, na linha, seguidas da mesma letra maiúscula não diferem entre si pelo teste de Tukey, a 5\% de probabilidade de erro

Médias, na coluna, seguidas da mesma letra minúscula não diferem entre si pelo teste de Tukey, a 5\% de probabilidade de erro

Ciência Rural, v.39, n.6, set, 2009. 
Ressaltam-se os baixos depósitos da ponta TX-6, uma vez que esta gera gotas finas, os quais teoricamente teriam maior probabilidade de penetração em plantas de elevado dossel. Essacquestão, foi destacada por BARBER et al. (2003), os quais justificaram a maior eficácia de fungicidas com gotas finas pela maior capacidade de contato dessas gotas do fungicida com esporos. No entanto, os resultados são comparáveis aos registrados por BAUER (2002). Nesse estudo, em soja com abundante dossel de folhas, a ponta TX-4 apresentou o pior comportamento. Embora tenham maior probabilidade de penetração, as gotas finas também tem altas probabilidades de perdas por deriva. Esses resultados indicam que, nas aplicações com pontas TX, é preciso utilizar volumes superiores a 200L ha-1.

A comparação de ambas as cultivares na deposição, na região basal (Tabela 2), foi semelhante ao acontecido na avaliação da região apical. As pontas AI 250L ha ${ }^{-1}$ e TJ 150L ha ${ }^{-1}$ apresentaram menores depósitos na cultivar 'CD 216'. O mesmo comportamento foi verificado nessa região para a ponta AI $150 \mathrm{~L} \mathrm{ha}^{-1}$. Resultados similares foram obtidas na avaliação da planta inteira (Tabela 3). A deposição na região basal, embora com valores baixos de depósitos, apresentou mais homogeneidade nos valores das médias, o cálculo dos desvios absolutos das medias dos tratamentos denota isso (46 e 15 na região apical e basal, respectivamente).
Aém disso, SCRAMIN et al., (2002), em um estudo de deposição de pontas na cultura do algodão, obtiveram menores deposições na região basal.

O uso do modelo de Gompertz permite, a partir da análise das frequências acumuladas e não acumulada, identificar as pontas de maior uniformidade na distribuição dos depósitos, segundo o grau de curtose da curva. Essa questão foi discutida por TOFOLI (2001), o qual afirmou que o uso do modelo é uma boa ferramenta para ser utilizada nos estudos de deposições de aplicações de defensivos agrícolas, já que a análise a partir da média não é suficiente.

Nas figuras $1 \mathrm{~A}$ e $1 \mathrm{~B}$, das freqüências não acumuladas, destaca-se o comportamento da ponta AI no maior volume avaliado, como a de menor uniformidade na deposição da calda em ambas as regiões das plantas na cultivar 'CD 208'. Quanto menor a curtose das curvas de frequências não acumuladas, maior será a uniformidade de deposição da calda de pulverização (PALLADINI, 2000). No entanto, a ponta TX-6 150L ha-1 apresentou a menor variação quando comparada às outras pontas e aos outros volumes, com volume menor de depósitos, e apresentou menor frequência de valores extremos na deposição de modo semelhante à ponta TJ 200L ha ${ }^{-1}$. Porém, as duas deslocadas para esquerda indicaram importante assimetria na distribuição dos depósitos.

Tabela 2 - Comparação da deposição da calda de pulverização ( $\mu$ L.g ${ }^{-1}$ massa seca) nas cultivares ‘CD 208' e 'CD 216’ em R1 na região basal. Botucatu/SP, 2005.

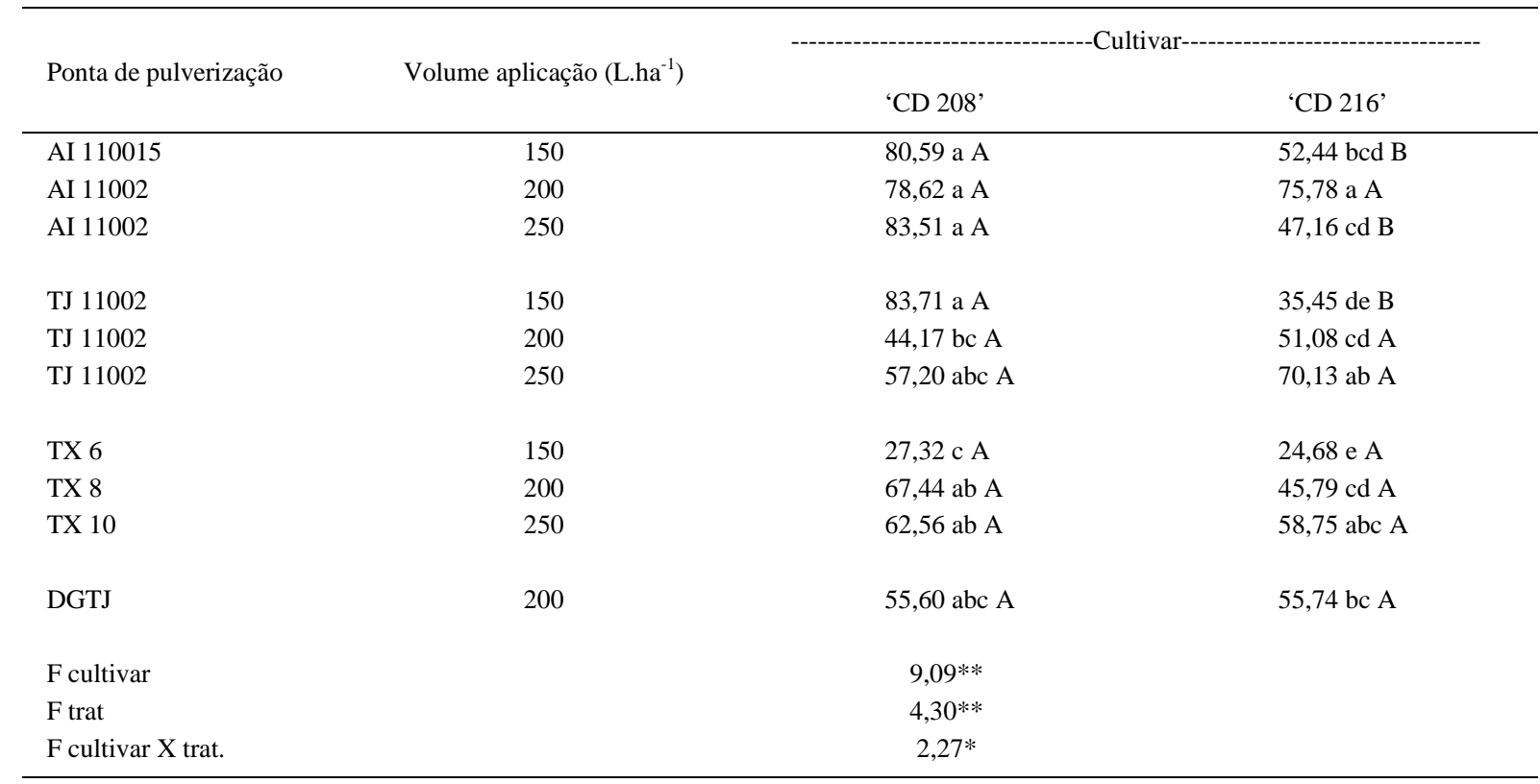

Médias na linha, seguidas da mesma letra maiúscula não diferem entre si pelo teste de Tukey um nível de 5\% de probabilidade de erro. Médias na coluna, seguidas da mesma letra minúscula não diferem entre si pelo teste de Tukey um nível de $5 \%$ de probabilidade de erro.

Ciência Rural, v.39, n.6, set, 2009. 
Tabela 3 - Comparação da deposição da calda de pulverização ( $\mu \mathrm{L} . \mathrm{g}^{-1}$ massa seca) nas cultivares ‘CD 208' e ‘CD 216’, em R1, na avaliação de planta inteira. Botucatu/SP, 2005.

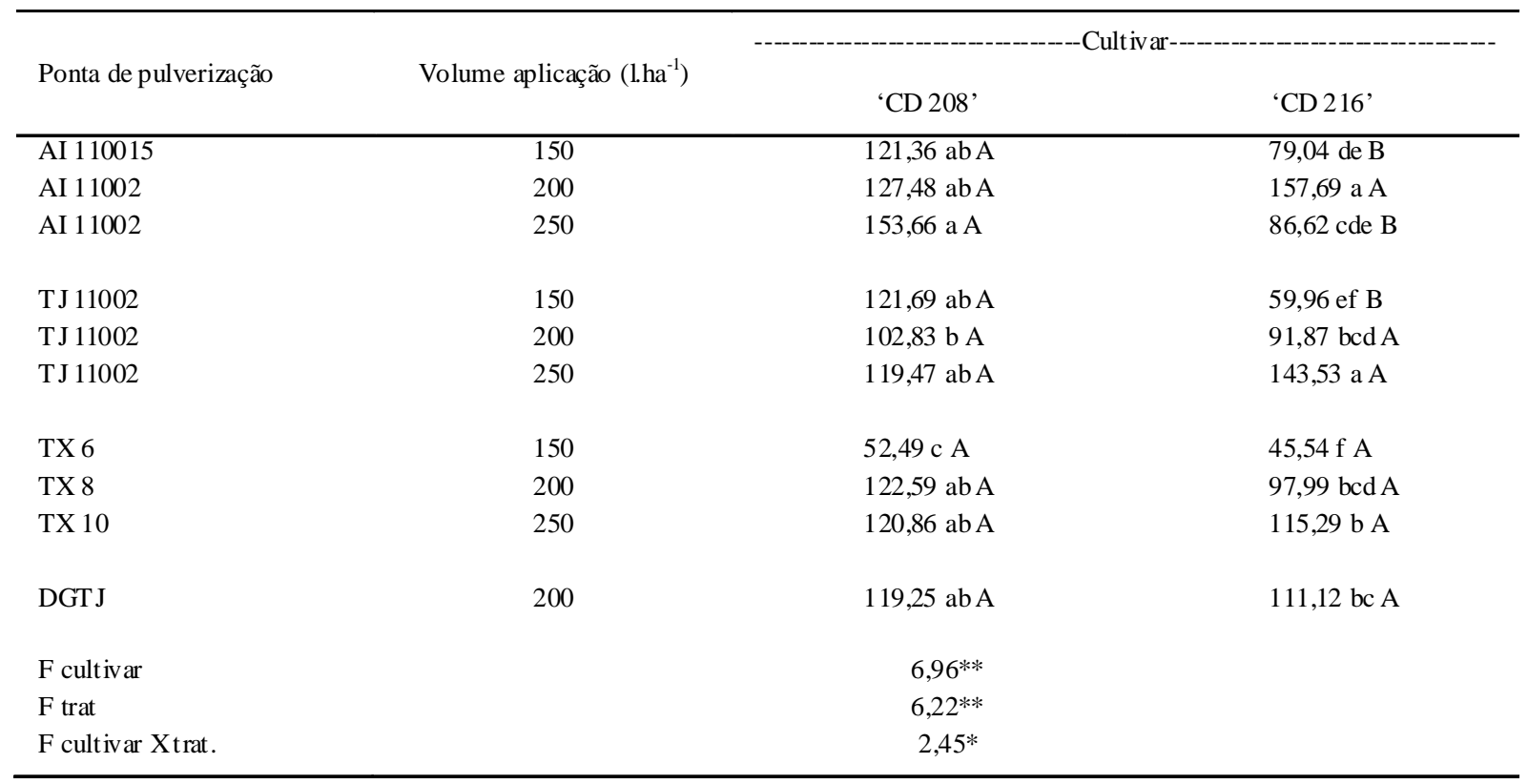

Médias, na linha, seguidas da mesma letra maiúscula não diferem entre si pelo teste de Tukey, a 5\% de probabilidade de erro Médias, na coluna, seguidas da mesma letra minúscula não diferem entre si pelo teste de Tukey, a 5\% de probabilidade de erro.

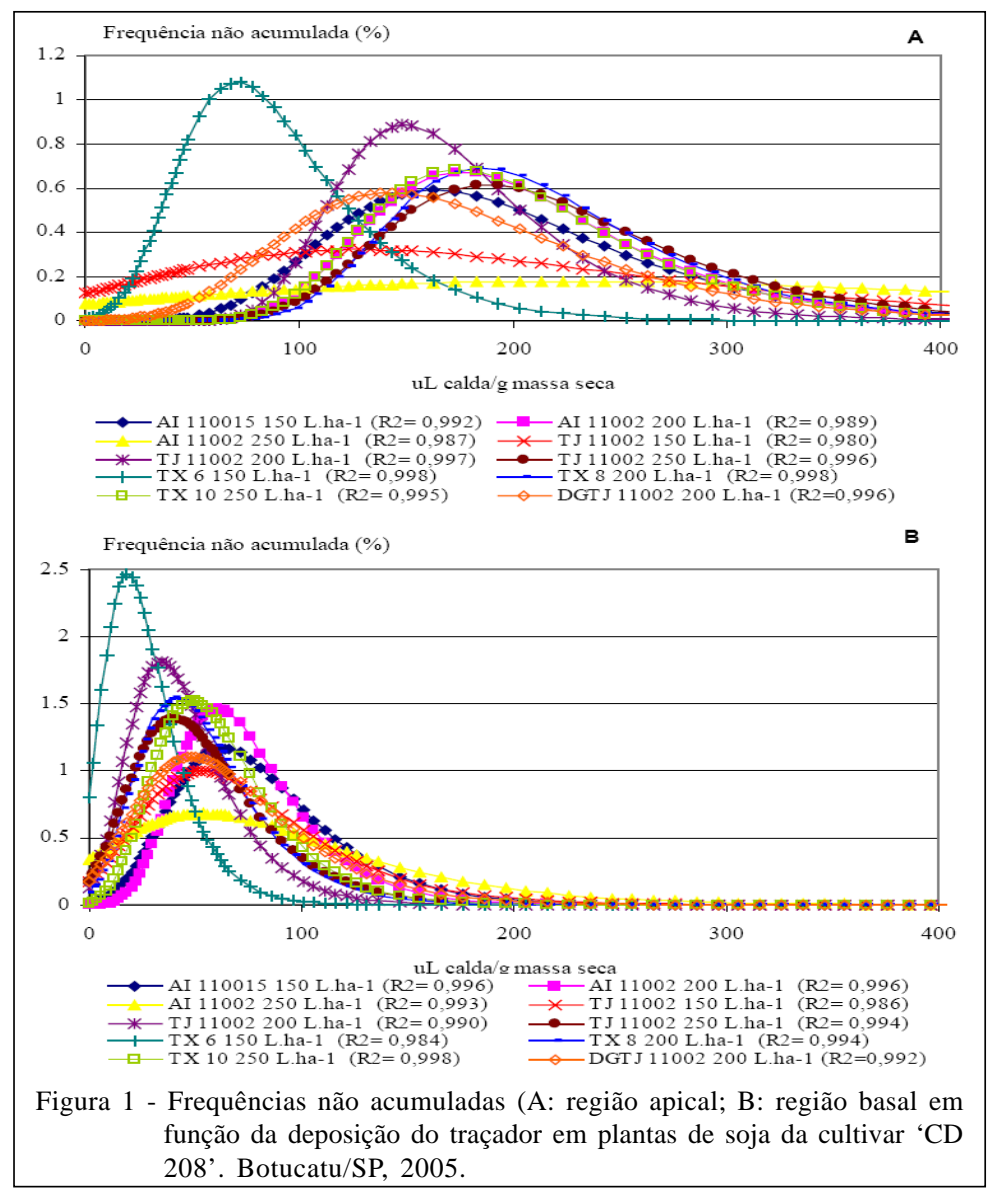

Ciência Rural, v.39, n.6, set, 2009. 
Esses resultados possibilitam a discussão da importância da distribuição das gotas para distintos pesticidas utilizados, como os produtos de tipo sistêmico, que não apresentam elevada dependência da distribuição dos depósitos, assim como os de contato. Isso reforça a idéia de que uma maior deposição obtida, a partir da média do tratamento, não foi suficiente para oferecer respostas em tecnologia de aplicação, já que nesse valor da média pode existir uma alta frequência de valores extremos, sendo então deficiente a uniformidade da distribuição da calda. MARTINS (2004) obteve dados concordantes na cultura da batata, no qual a maior deposição em plantas foi a de menor uniformidade.

No entanto, em uma avaliação de cobertura da aplicação em diferentes regiões da planta de soja, ANTUNIASSI et al. (2004) não comprovaram efeitos das pontas de pulverização (TX, TJ, XR, AI). Esse resultado está de acordo com o estudo de controle de doença em fejoeiro de CUNHA et al. (2005), no qual não houve diferenças nos depósitos e nem no controle da doença por efeito da aplicação com pontas de jato plano, jato plano antideriva e cônico vazio. Isso, indica que mais importante que o desenho da ponta é o espectro de gotas geradas pelas condições de uso delas. Os resultados da deposição na planta inteira mostraram um comportamento similar aos depósitos observados nas regiões apical e basal da planta.

$\mathrm{Na}$ cultivar 'CD 216', os melhores tratamentos visualizados nas curvas da frequência não acumulada (Figura 2A e 2B) indicam que as pontas TX e TJ nos volumes de $150 \mathrm{~L} \mathrm{ha}^{-1}$ foram as que apresentaram maior uniformidade na distribuição da calda de pulverização, com menores variações dos depósitos unitários. No entanto, as pontas com depósitos de maior variação foram as AI no volume de 200L ha-1, e a TJ, no maior volume. Na região basal, similar ao que aconteceu com a cultivar 'CD 208', os depósitos apresentaram menor variação, e todas as pontas tiveram um comportamento muito similar. Esses resultados permitem concluir que as duas cultivares apresentaram comportamento similar em relação à quantidade de calda depositada. CUNHA et al. (2006), em um estudo de aplicação de fungicida para o controle de ferrugem asiática, no qual avaliaram a uniformidade por meio da deposição entre as faces das folhas superiores e inferiores das plantas, obtiveram maior uniformidade com os maiores volumes.

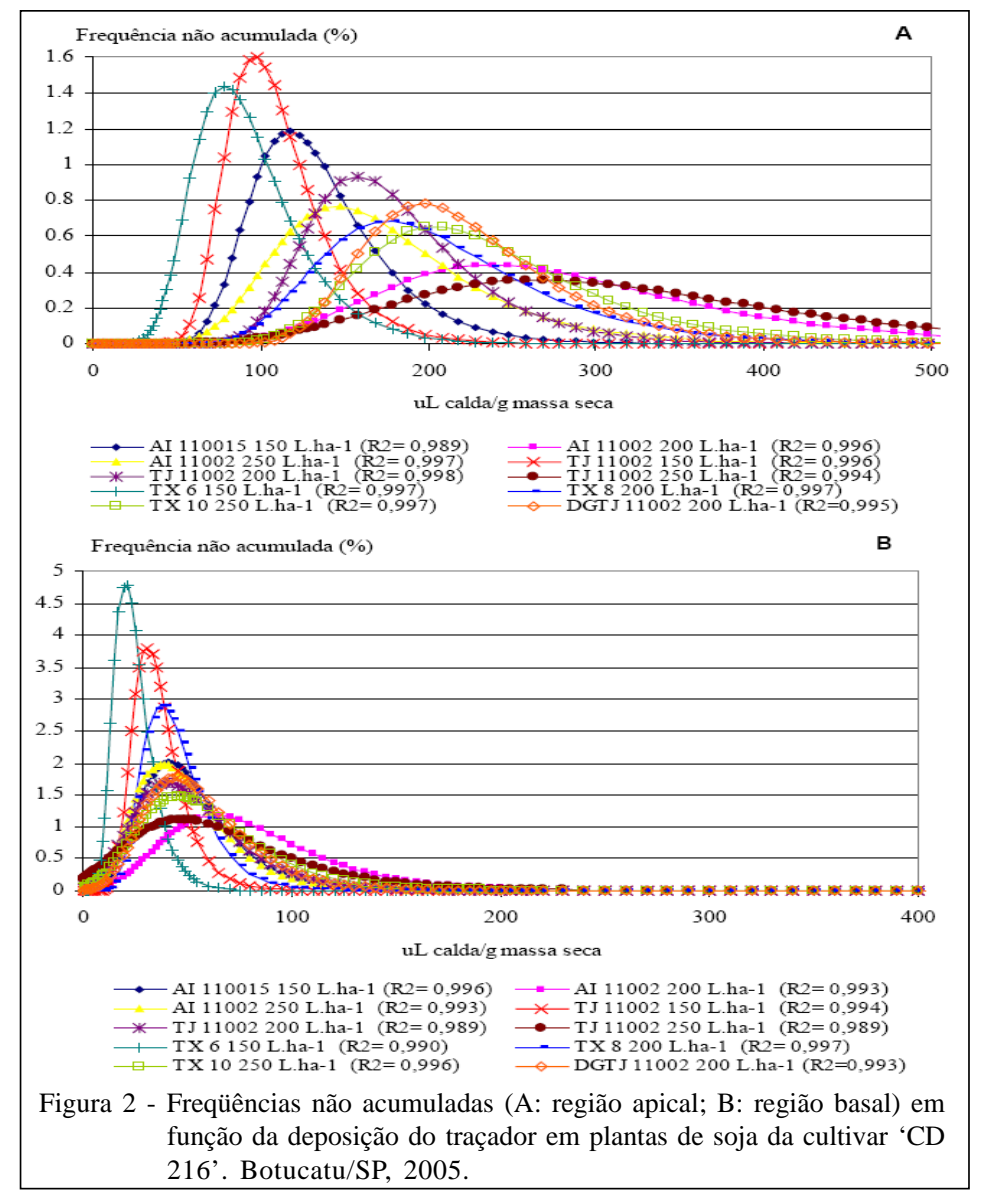

Ciência Rural, v.39, n.6, set, 2009. 


\section{CONCLUSÕES}

Para as condições desses experimentos, os depósitos na região apical foram quase três vezes superiores aos da região basal. Geralmente, os maiores depósitos corresponderam aos tratamentos com os volumes maiores avaliados, sendo as pontas AI 250L ha ${ }^{-1}$ e TJ 250L ha'-1 nas cultivares 'CD 208' e 'CD 216', respectivamente.

Ressalta-se a contradição entre os parâmetros avaliados de quantidade de depósitos e uniformidade na distribuição. Em todas as avaliações, os tratamentos de maiores depósitos geralmente foram os de menor homogeneidade.

\section{REFERÊNCIAS}

ANTUNIASSI, U. et al. Avaliação da cobertura de folhas de soja em aplicações terrestres com diferentes tipos de pontas. In: SINTAG, SIMPÓSIO INTERNACIONAL DE TECNOLOGIA DE APLICAÇÃO DE AGROTÓXICOS, 3., 2004, Botucatu. SP. Anais... Botucatu: FEPAF, 2004. p.48- 51.

BARBER, J.A.S. et al. Effect of application method on the control of powdery mildew (Bulmeria graminis) on spring barley. Crop Protection, v.22, p.949-957, 2003.

BAUER, F.C. Distribuição e deposição da pulverização sob diferentes condições operacionais na cultura da soja (Glicine max (L.) Merrill). 2002. 130f. Tese (Doutorado em Agronomia/ Proteção de Plantas)- Faculdade de Ciências Agronômicas, Universidade Estadual Paulista, Botucatu, SP.

CUNHA, J.P.A.R. et al. Avaliação de pontas de pulverização hidráulicas na aplicação de fungicida em fejoeiro. Ciência Rural, v.35, n.5, p.1069-1074, 2005. Disponível em: http:// www.scielo.br/pdf/cr/v35n5/a13v35n5.pdf. doi: 10.1590/ S0103-84782005000500013.
CUNHA, J.P.A.R. et al. Controle químico da ferrugem asiática da soja em função de ponta de pulverização e de volume de calda. Ciência Rural, v.36, n.5, p.1360-1366, 2006.

LIMA, P.R.F.; MACHADO NETO, J.G. Otimização da aplicação de fluazifop-p-butil em pós-emergência na cultura da soja (Glycine max). Planta Daninha, v.19, n.1, p 85-95, 2001.

MAROCHI, A.I. Tecnologia de aplicação de defensivos agrícolas. In: SIMPÓSIO INTERNACIONAL SOBRE SEMEADURA DIRETA EM SISTEMAS SUSTENTÁVEIS, 1993, Castro-PR. Anais... Castro-PR: Fundação ABC, 1993. p.208-227.

MARTINS, D. Deposição de calda de pulverização em cultivares de batata. 2004. 249f. Tese (Livre docente em Agricultura)- Faculdade de Ciências Agronômicas, Universidade Estadual Paulista, Botucatu, SP.

PALLADINI, L.A. Metodologia para avaliação da deposição em pulverizações. 2000. 111f. Tese (Doutorado em Agronomia/ Proteção Vegetal)- Faculdade de Ciências Agronômicas, Universidade Estadual Paulista, Botucatu, SP.

SCRAMIN, S. et al. Avaliação de bicos de pulverização de agrotóxicos na cultura do algodão. Pesticidas: Revista Ecotoxicologia e Meio Ambiente, v.12, p.43-50, 2002.

TOFOLI, G.R. Efeito do tamanho do alvo e condições operacionais sobre a uniformidade de deposição pulverizações em pré- emergência. 2001. $62 \mathrm{f}$. Dissertação (Mestrado em Agronomia /Proteção de Plantas)Faculdade de Ciências Agronômicas, Universidade Estadual Paulista, Botucatu.

VELINI, E.D. Estudos e desenvolvimento de métodos experimentais e amostrais adaptados a matología . 1995. 250f. Tese (Doutorado em Agronomia/ Produção Vegetal) Faculdade de Ciências Agrárias e Veterinárias, Universidade Estadual Paulista, Jaboticabal, SP. 